\title{
CORRIGENDUM, VOLUME 78
}

B. Weiss, The isomorphism problem in ergodic theory, pp. 668-684.

Reference [30] in the above paper should read:

30. S. M. Rudolfer and K. M. Wilkinson, The independence properties of certain number theoretic endomorphisms, Proc. Sympos. on Topology, Dynamics and Ergodic Theory, University of Kentucky, Lexington, Ky., 1971, 68-69.

The omission of the second author is due to the error of the first when writing up the abstract quoted by Professor Weiss. The joint work announced there will be appearing shortly in Math. Systems Theory 6.

\section{ERRATUM, VOLUME 77}

Ping-Fun Lam, On a theorem of B. von Kerékjártó, pp. 230-234.

Page 232. Read "lim $\inf \{d(x t, y t) \mid t \in T\}=0 "$ as "inf $\{d(x t, y t) \mid t \in T\}=0$."

Page 233. Lines 17 to 19 should read "(IV) If $X$ is noncompact with boundary, then $X$ is topologically the closed half of the Euclidean $n$-space." 